July - 2005

\title{
Selected Topics from a Matched Study between a Face-to-face Section and a Real-Time Online Section of a University Course
}

\author{
Mia Lobel \\ Concordia University \\ Canada \\ Michael Neubauer \\ Stanford University \\ USA \\ Randy Swedburg \\ Concordia University \\ Canada
}

\begin{abstract}
Two sections of an interpersonal skills building university course were observed for the purposes of this matched study. The face-to-face (F2F) section was in a classroom on the Concordia University campus in Montreal, Canada, while the non-turn-taking real-time online section used a Web application, LBD eClassroom $₫$ designed specifically for highly interactive large size classes and meetings. Two sections used the same instructor, facilitators, pedagogy, and course content. This study revealed a unique pattern of non-turn-taking synchronous interaction in the online section. Online students were found to be more likely to participate and express themselves. Interaction of online participants led to the creation of a group entity - a polis - a cornerstone for collaborative group learning. In contrast, in the F2F section, interaction followed the traditional classroom pattern - centered on the teacher or expert, resulting in fewer students interacting, and hence, lower interaction overall. In sum, during these three hour sessions, it was found that the nature of online non-turn-taking environment afforded online students more time to express themselves compared to students learning the same material F2F.
\end{abstract}

\section{Introduction}

In 2001, Concordia University in Montreal Canada funded a matched study to determine the differences - if any - between a similar the online courses and face-to-face (F2F) courses. This paper describes two findings from this study.

“AHSC/230 Interpersonal Communication and Relationships,” offered by in the Applied Human Sciences Department of Concordia University, was the subject of this matched study. Section BB was offered F2F. Section CC was offered online. The same instructor taught these two sections 
Selected Topics from a Matched Study between a Face-to-face Section and a Real-Time Online Section of a University Course

Lobel, Neubauer, \& Swedburg

F2F and online, using the same pedagogy and same team of facilitators. Both sessions were divided into sub-parts, wherein all students met together or broke out into separate groups.

Results section of this paper is divided into two parts. In Part I, a group dynamics diagnosis was used to describe how the group develops, evolves, and becomes a productive entity over the course of one semester. In Part II, a single activity and processing period are studied in detail in terms of: 1) interactivity and use; and 2) perception of time.

\section{Methods and Measurements}

\section{Face-to-face}

Except for the presence of video cameras and crew, the F2F section took place in a traditional classroom setting at Concordia University in Montreal, Canada. The entire course was videotaped.

\section{Online}

LBD eClassroom $(c)$ is a text and image Web-based application designed to host large online classes and meetings in a non-turn-taking synchronous environment. The LBD eClassroom $₫$ has attributes not found in conventional chat rooms - eClassroom $\mathbb{C}$ is designed to provides a synchronous online environment analogous to highly interactive F2F courses (Neubauer and Lobel, 2003). LBD eClassroom $₫$ has been used at Concordia University to teach online university courses for the last four years.

\section{Data Collection}

The F2F section was videotaped from beginning to end. Data collection for the F2F section included questionnaires, weekly journals, assignments, emails, and the manual review of the videotapes. Data collection for the online section included questionnaires, weekly journals, assignments, emails, and the LBD eClassroom $(\mathcal{C}$ digital archives of online student activities.

\section{Participants}

Students ( $n=21$ females; $n=7$ males) enrolled in the F2F class; all 28 students completed the course. Thirty-three students ( $n=27$ female; $n=6$ male) enrolled in the online class; 32 students completed the course. One student (female) withdrew for medical reasons from the online course. Counting staff, guests, and observers, the typical size for the online class numbered 40 participants. The F2F class, numbered 35 participants, including students, instructional, and audio/ visual recording staff.

\section{Content and Pedagogy}

The teaching modules used for both the F2F and online class were designed using Kolb's Theory of Experiential Learning (Kolb, 1984). Both classes were tailored to deliver the same material, underpinned by the same theoretical learning cycle concepts: Inclusion, Concrete Experience, Reflective Observation, Abstract Conceptualization, Active Experimentation, and Weekly Journals. 
Selected Topics from a Matched Study between a Face-to-face Section and a Real-Time Online Section of a University Course

Lobel, Neubauer, \& Swedburg

Both classes met at first in the larger community and, eventually, after the Inclusion cycle, the Concrete Experience, the ensuing Processing, the Lecturette, and the Break, were dispersed into four smaller groups identified by the colors: Blue, Green, Purple, and Orange.

The template used to design the three hour teaching modules for both sections was built upon the instructor's 25 years of teaching in F2F settings, and three years of online teaching of courses in interpersonal communications and group dynamics.

\section{Inclusion (15 Minutes)}

At the beginning of each session - both F2F and online - participants were asked to familiarize themselves with each other by engaging in a safe activity. Content took the form of poems, meditation pieces, fables, quotes, and images. During this safe activity, participants tested each others' responses and established expectations, a process called 'gobletting,' which Schultz (1988) says refers to strangers meeting, holding their goblets, and talking about inconsequential things.

F2F students sat in a large circle facing each other. The instructor began each F2F session with a Progressive Relaxation exercise (Lazarus, 1975), and read aloud the material posted in the eClassroom. Online students read the same material between sessions, but did not engage in the Progressive Relaxation exercise.

\section{Concrete experience (30 Minutes)}

Each F2F and online session started with an activity aimed at providing students with an experience that moves them toward the objectives of the class (see Appendix I). This activity is consistent with Dewey's concept that students' nature of experience is fundamental in education and training (Dewey, 1938; 1997). The Confucian quote (circa 450 BC): "Tell me, and I will forget. Show me, and I may remember. Involve me, and I will understand," is an excellent way to describe the intent of the Concrete Experience component. Activities, such as role playing, games, and other collaborative tasks, are designed to build participants' awareness of the experience (i.e., establishing students' relationships in terms of trust or assertiveness, or in terms of conflict or diversity, to name just two examples). Students are also instructed to observe their activities, yet not curtail their reactions (as much as possible).

\section{Processing or reflective observation (30 Minutes)}

Reflective Observation involves description, communication, and learning from the Concrete Experience. During the Concrete Experience activity, students were given "process questions" to elicit reactions inside themselves and with other participants, from which they were to formulate learning goals. Examples of the "Process Questions" are: What helped/ hindered your experience? How would you describe your reactions? What are some of the strengths/ limitations you brought to this experience? What would you like to change and how?

\section{Abstract conceptualization or "lecturette" (25 - 60 Minutes)}

The group synthesized the data generated during the Reflective Observation Processing section phase of the teaching module. In the F2F class, the instructor facilitates Kolb's Abstract Conceptualization using a "Lecturette" designed using a serial turn-taking discussion format. In the online class, the Lecturette is posted on the LBD eClassroom $\subset$ using illustrated slides. After 
Selected Topics from a Matched Study between a Face-to-face Section and a Real-Time Online Section of a University Course

Lobel, Neubauer, \& Swedburg

reading the Lecturette, online students respond online to the instructor, to their facilitators, and to each other, thereby linking the course material to their experience in an interconnected web of non-turn-taking, free-flow of statement/ response discussion - thereby creating the noteworthy dynamic in which the synchronous online environment imposed its own demand, and thus accounted for several important differences presented in this paper.

\section{Active experimentation (30 - 60 Minutes)}

Active Experimentation consists of topic-related activities that allow participants an opportunity to practice new behaviors and follow up on the learning goals identified previously during the Reflective Observation/ Processing section of a teaching module. At this juncture, classes breakout into smaller groups. Active Experimentation affords students greater opportunity to engage in risk-taking and practice, and typically concludes with a small group Processing or Reflective Observation session.

\section{Weekly journals}

To facilitate Reflective Observation/ Abstract Conceptualization, the use of Weekly Journals guide students through a review of their learning cycle (Kolb, 1984) using Reflective Observation/ Abstract Conceptualization activities. Students use their Weekly Journals to record their observations, link their observations to theoretical concepts, and formulate a concrete, measurable, observable plans designed to engage the learner in change and/or acquire a selfidentified skill.

\section{Results Part I}

\section{A Group dynamics diagnosis}

One method to diagnose group development is to examine interconnected areas of a group's dynamics (Dimock, 1985). The "Physical Climate" is one such an area (which is usually paired in discussion with the "Emotional Climate"). In F2F settings, the "Physical Climate" influences the group's dynamics in terms of space, lighting, ventilation, acoustics, temperature, seating arrangements, and so on (Dimock, 1985).

In online settings, however, each participant is typically at home and thus has control using over their physical environment. Comments about working in pajamas, working on kitchen tables, while lounging on sofas, or outside in the sunshine are examples of "chatter" commonly found in online conversations. In the LBD eClassroom $(\mathbb{C}$, one's classroom is the size of their computer screen. Some students enter this space and know how to use it right away, while others need some time to get comfortable with the environment.

During the first class, students are divided into the four colour-coded breakout groups. Students’ initial concerns tend to center on resolving their need for "Inclusion" in the group (Schultz, 1988). "Inclusion" here is exemplified by the behaviors students use to show their individuality or claim a spot in group membership. Activities such as finding the right colours or the right buttons to click tends to be overshadowed by students' sense of urgency to "show a face" - i.e., upload their pictures. During this "inclusionary phase," other areas of group development tend to basically nonexistent. Involvement at this phase is totally self-focused and oriented, whereas group oriented participation is erratic and idiosyncratic. In short, there is little group cohesion and joint decision making at this point, and leadership is generally not yet evident or ignored. 
Selected Topics from a Matched Study between a Face-to-face Section and a Real-Time Online Section of a University Course

Lobel, Neubauer, \& Swedburg

In contrast, in F2F classes the "Inclusion" phase tends to be orderly and tightly managed by the instructor. It is not unusual for students to initially express surprise and display some minor discomfort, as the Applied Human Sciences Department's norm for this course involved everyone sitting in a circle, facing each other with no desks to act as boundaries. The cameras and camera crew also contributed to the de-familiarization of the F2F environment. However, the instructor, by using Inclusion oriented behaviors and activities, managed to create a warm, light, and supportive emotional climate during the first F2F class. Students took turns to introduce themselves; there was much humor and hand clapping. Facilitating activities, such as sorting students into break-out groups, were as simple as handing each student a piece of paper and pointing out the four group facilitators.

As recorded in the Weekly Journals, F2F students reported that their session was highly personal from the outset, with feelings of collegiality and camaraderie that appeared to deepened over time. Online students, on the other hand, first reported being at unease, feeling chaos, and sensing frustration - feelings which over time were replaced by a slow-growing sense of closeness (it must be noted here, that feelings of 'closeness,' however, remained tepid in larger online classes). During the small group sessions, however, online students reported that the emotional climate was open, accepting, supportive, and collaborative - a finding similar to that recorded by F2F students in their journals.

Our finding - that students in smaller online classes reported an emotional climate that is apparently similar to F2F students - raises an important question: If students in small online groups rated their satisfaction to be "open," "accepting," "supportive," and "collaborative," is it possible that they experienced perhaps even greater, more intense feelings than their F2F student counterparts? Clearly, this is a valid question that deserves further in-depth study.

By the last session of AHSC/230 Interpersonal Communication and Relationships, students in both F2F and online sections reported that they had learned to participate to the extent that each environment can allow. Both groups of participants reported that they felt involved and part of their 'class,' that they engaged in group decisions, and were supplied with leadership functions necessary to feel productive and satisfied with themselves and with the group.

A video camera recorded F2F students - i.e., which person participated verbally and nonverbally. However, for instructors seeing students sitting in class in silence and without the ability to read individual students' minds, only the student knows for sure her or /his "quality" of being attentive. This can be compared with the LBD eClassroom $($, which has been designed to record and gather data on how students are "attending." As such, it is possible to extrapolate the level participant's' behavior beyond that of than simply posting a comment (Lobel, Neubauer, and Swedburg, 2002b).

Another way to make sense of group interaction and group development is to classify the content of all statements exchanged between participants, in both F2F and online contexts. Classifications can be either addressing the task/content; maintenance/ process of the self/ group. To achieve optimal group productivity, it is necessary to find a balance between the task-oriented and maintenance-oriented communication (Dimock, 1985). Our inquiry reveals that both the F2F and online groups functioned reasonably well, and the task-oriented and maintenance-oriented functions were similarly well attended.

It is also suggested here that the nonverbal statements exchanged F2F are also being exchanged online. Qualitatively, posting online comments that contain emoticons, one word or two word comments, icons, gifs, and colored text, etc., form a shared experience for each online participant. 
Selected Topics from a Matched Study between a Face-to-face Section and a Real-Time Online Section of a University Course

Lobel, Neubauer, \& Swedburg

This finding is confirmed by Kellogg and Erickson (2002) who state: "Collective awareness occurs when two or more people are aware of the same context and each is aware that the others are aware of it. Although subtle, this awareness of others' awareness is crucial to supporting collaboration. Collective awareness underlies social phenomena like peer pressure, accountability, and competition” (pg., 1).

\section{Results Part II - Interactivity}

Activity can center on the task and/or course content - specifically, what is being done. Activity can center on maintaining social relationships or the process - specifically, how it is being done (Dimock, 1985). Consider an orchestra. The content is the score for all the musical parts. The process is the performance of the music when the parts of the score are played together. The resultant symphony is greater than the sum of all the parts that went into it.

A group's symphony may be analyzed in similar ways. Socio-metric measures, a method of socio-psychology developed by the psychiatrist Moreno (1934), can be applied to analyze interpersonal emotive relationships within a group. These methods can be used to identify informal leaders, determine social rankings within the group, and reveal isolated individuals.

Creating "social visualizations" is another way to conceptualize the process of inquiry. A social visualization is a visual (sonic or other perceptual) representation of information from which the presence, activities, and other characteristics a social collectivity may be inferred, and, by extension, can provide the basis for making inferences about the activities and characteristics of the group as a whole (Light, 2003; Kellogg and Erickson, 2002).

Interactivity can be observed and measured by figuring out: Who speaks to whom? How often? How long? Who are the over/ under participators? Some of the socio-metric instruments used to make sense of the data collected for this study were: Participation Pattern Diagram (Lobel, et al., 2002b) based on the Interaction Diagram (Dimock, 1985), the GUIDATA $@$ (Lobel et al., 2002b), the Hubs of Influence Diagram (Lobel et al., 2002b), the spoken length of written words, and the elapsed time of a participant's F2F statement.

\section{Methodology}

Participation pattern diagrams were created by using the social networking software, Ucinet (Borgatti, Everett, and Freeman, 1999) and Pajek (Batagelj and Mrvar, 1996). The center of the diagram is defined as the hub of authority (Lobel et al., 2002b), and represents the participants to whom most of the statements were directed. The farther the participant's name is from the center of the diagram, the fewer statements that particular participant directed toward the center hub of authority. Every directed interaction (who spoke to whom) is represented by a line between the sender and the receiver of the statement or comment, with an arrow pointing to the receiver.

\section{Results}

We chose one session at random to compare the online and F2F interaction. The data displayed in Figures 1 and 2 use a typical Participation Pattern Diagram, reflecting what was generally found in general in the two environments. This Participation Pattern Diagram describes who spoke to whom and how often over a period of 30 minutes in the two learning environments: F2F and online. Students were asked to 'mill around,' find three people who exhibited an ascribed attribute (i.e., spoke four languages, had children, etc.), and engage in brief discussions with as 
Selected Topics from a Matched Study between a Face-to-face Section and a Real-Time Online Section of a University Course

Lobel, Neubauer, \& Swedburg

many other students as possible. During the Processing Periods shown in Figures 1 and 2, students were asked to discuss how they fit in, how they connected, what interpersonal skills helped, and what interpersonal skills others used to connect.

Different patterns emerged that defined the manner and method of participation among members of the online class and F2F class.

Figure 1. Online Session 2 Participation Pattern Diagrams for 30 minutes of processing after the activity. "S" refers to the students, "PI" refers to the principle instructor, and "F" refers to the facilitators.

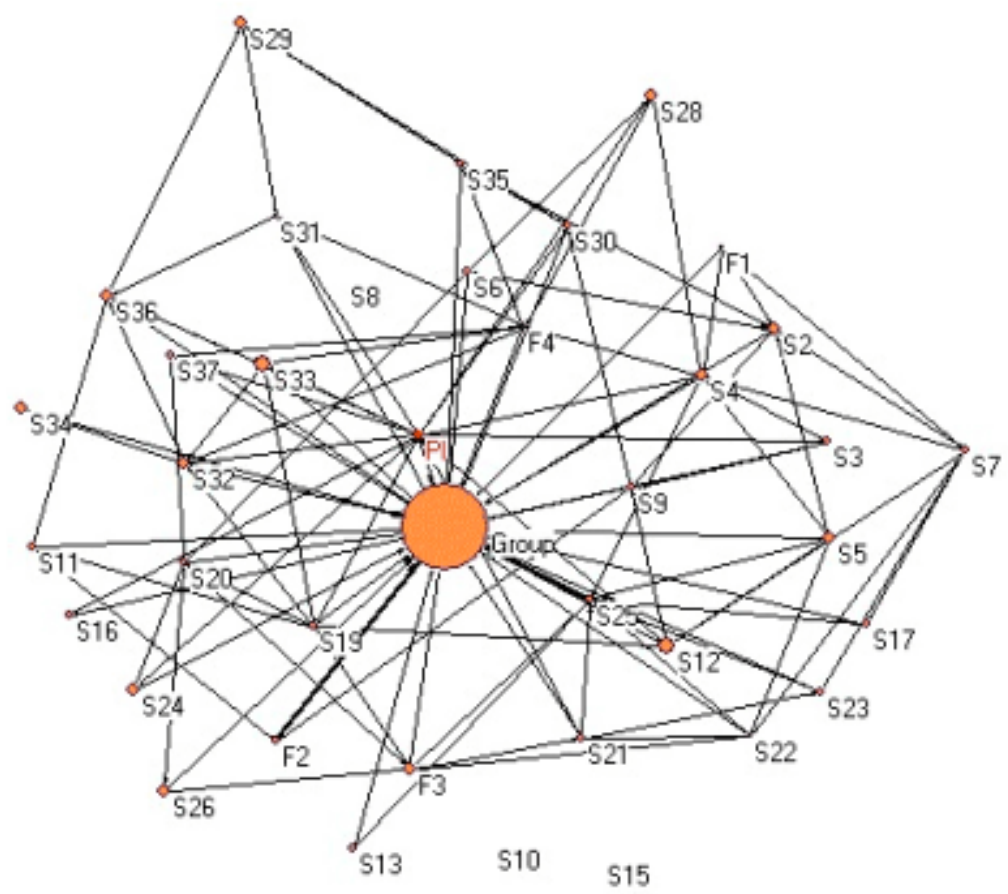


Figure 2. Face-to-faceF2F Session 2 Participation Pattern Diagrams for 30 minutes of processing after the activity. "S" refers to the students, "PI" refers to the principle instructor, and "F" refers to the facilitators.

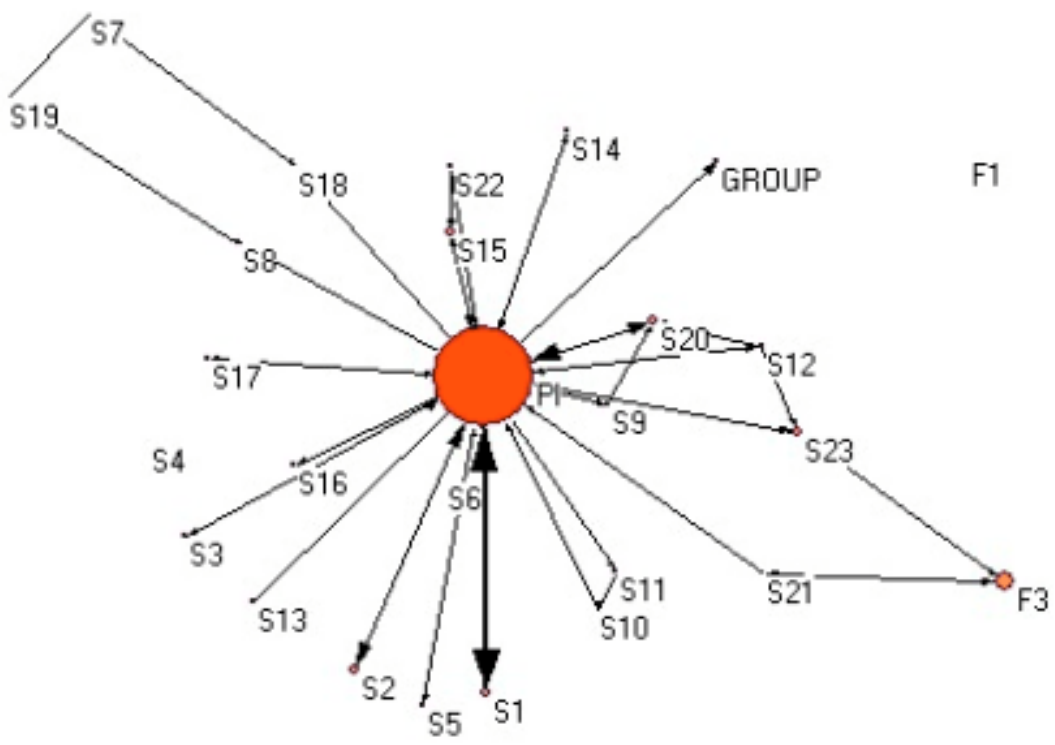

Figure 1, shows 100 percent participation by all 33 online students. Figure 2, on the other hand, reveals 82 percent $(n=23)$ participation among students in F2F class $(n=28$ registered students), for a ratio of 23:28 students. The overall percentage of participation is a facet of interactivity in which the data reveals as different for the two environments. Typically, the percentage of online participation remains 100 percent over time; during each online session, all students contribute something to the group narrative. In the F2F sessions, however, the percentages of students participating verbally varies from 82 percent (during discussions) to 10 percent (during lectures), and only reaches 100 percent if students are specifically requested to do so by the instructor, or by the activity assigned.

\section{Discussion}

An important difference between the online and F2F class is the central hub of interaction. In online discussions, it is the group entity (polis) that is at the center of the diagram, while during F2F discussions it is the instructor who is the central hub. In the online class, more student statements were addressed to the group entity/ polis, than to the instructors or each other individually. Conversely, students in the F2F class addressed the instructor more often than they addressed each other. Another interesting observation from this sample is that the group entity does not appear to have the same prominence or influence in the traditional F2F environment as it did online.

This evidence suggests that this group-centered versus authority-centered pattern of interaction shows a fundamental value shift in the teaching paradigm for this type of course. An interactive classroom used to teach interpersonal skills is expected to serve as an arena in which appropriate self-disclosure, feedback, and discovery take place. Openness and translucence are seen as factors 
Selected Topics from a Matched Study between a Face-to-face Section and a Real-Time Online Section of a University Course

Lobel, Neubauer, \& Swedburg

that facilitate the trust formation needed to risk these types of interpersonal behaviors. This is true in F2F classrooms. Online, however, the process itself is even more inherently transparent everyone can see all the ingredients that go into the ongoing class narrative. One of the objectives of this type of class is that all the students participate and collaborate in constructing communication knowledge and relational skills.

It is postulated, therefore, that many of the interactions that online are explicitly addressed to the group entity or polis (e.g., narrative such as "sigh" or emoticons) are collapsed into non-verbal interactions in F2F settings. These non-verbal interactions saturate the atmosphere of the humbuzz of F2F group babble (i.e., music of the group), and are exchanged in dyads, or sub-vocally, or with instruments like pens clicking, fingers drumming, etc. It is postulated here, therefore, that some of the online statements addressed to the group entity may serve a similar function as the F2F hum-buzz observed and recorded in the videos. Many online statements addressed to the group entity are pertinent and include constructive comments that in F2F settings could not have been exchanged or made available to the entire group due to natural time constraints built into the serial nature of F2F interaction (as discussed in the next section).

The online interaction patterns observed in this study substantiate that a group is a distinct entity formed by the sum of its members - more importantly, it shows that group interaction can become greater than the sum of all its parts, and comes complete with its own idiosyncratic character and life span. Specifically, the group entity phenomenon observed suggests that the power of the group to publish itself as a written document, which can be read and archived and re-read later, can resonate to others beyond that of the original group. No such opportunity occurs in F2F settings - even in videotaped sessions which only can record the group hum-buzz. These implications are fundamental to teaching and training settings that depend on collaborative learning, no matter where it occurs. In the online class, evidence of 100 percent participation and interaction among all participants attests to this group dynamic, one which can be measured and recorded, and which supported in findings from previous studies (Lobel, Neubauer, and Swedburg, 2002b). As any teacher knows, many participants in their F2F classes may remain silent - but look at the recorded dialog of the online synchronous class, you will see an abundance of dialog.

The Interaction Diagram for the online class points to interactions between many people, looping and overlapping, with some students participating in several loops. The closed loops represent multiple topic-related exchanges between the members and are seen as illustrations of building on the knowledge/ comments of others. Students in the online class created significantly more closed loops than the students in the F2F class; in this sample, everyone in the online class was addressed or responded to at least twice. In the F2F class, only five discussion loops are simple and observable: six participants remained silent; another six participants were addressed/ responded only once, and these exchanges only occurred between students and the instructor. In the online class, the loops are numerous, multi-layered, and complex, representing a fundamentally different mode of communication, an observation which was previously described in the literature (Lobel, Neubauer, and Swedburg, 2002a). The nature of the synchronous online communication in this study can described as: "non-turn-taking discussion," a type of discussion that creates complex and visible interconnectedness of a web.

During class discussions, online students have the advantage of the entire group's point of view (i.e., all views from instructors, facilitators, and peers). F2F students generally tend to derive benefit only from their instructor's statements. In addition, in the online class, the web of statements generated is recorded and remain accessible to all participants as exactly created, independent of memory, after the event is over. The Scroll Back and Archive functions are 
invaluable teaching and training tools that enable participants to refer back to the exact instructions or classroom narrative recorded earlier. Online participants use these functions for feedback on behaviors; to search for specific examples to illustrate statements; and even reconcile perceptions of an 'event' amongst themselves. This advanced level of archiving and functionality is simply not available in F2F settings.

The online Participation Pattern Diagrams show that the center of the group can be visualized as a 'physical space,' akin to the ancient polis, defined as a community center, or a place where community dialogue occurs. This definition implies a sacred ground, wherein its members exhibit and leave their offerings for all to see and use.

\section{Results Part II - Time}

Time and the perception of time has been identified as an area in which F2F turn-taking interactions differs significantly from online non-turn-taking interactions. The time allotted for F2F discussion is finite; time is progressively used up as each successive participant takes their turn to speak. In short, once time runs out for the entire group, it is over. Many online classes too are predicated on turn-taking interaction, such as that that occurs during audio and video presentations. In a non-turn-taking synchronous interaction environment, however, everyone has the same amount of time to interact and they can all interact simultaneously.

\section{Methodology}

The same time period and session analyzed in Figures 1 and 2 are now analyzed in terms of the use and perception of time.

A common metric was used to compare the text and image-based online class to the video recorded F2F class. We converted the words written in the online environment to an equivalent unit of time (15 words for each six seconds of speech). In the F2F class, the video time stamp was used to determine the start and stop time of each participant dialog (data segment) during the discussion period. The conversion factor - 150 words per minute (Sanderson, Siple, and Lyons, 1999, p.13) - is the hard word count for turn-taking auditory interactions (in any medium) needed to remain comprehendible. This conversion factor - 150 words per minute - means that 15 written words written equal six seconds of speech.

A software program was used to extract the data from the online archives and automatically create the graphic results. The F2F data, as observed from the videotapes of the sessions, was recorded manually.

\section{Results}

Figures 3 and 4 show how time was used in the discussion phase of both F2F and online sessions; these are plotted as Participation Diagrams in Figure 1 and 2. In addition to the 30 minutes of the processing period presented, Figures 3 and 4 contain the interaction during the "milling around" activity that preceded the discussion phase.

In the F2F class, the activity period is depicted as a solid green square (Figure 3), because participants were milling around the room, interviewing each other, and talking simultaneously. All individual utterances disappeared into the solid block of F2F group hum-buzz for 28 minutes. Subjectively, this collective experience was that of energetic, upbeat conversation, composed of 
everyone and representing no one. The length of each red bar corresponds to the length of time a participant took during the F2F turn-taking interaction. Once the Processing period begins, the red bars in Figure 3 clearly portray how the 30 minute time-frame was apportioned between the various participants, with the instructor using up the lion's share of time available.

Figure 3. Time-use in the turn-taking, face-to-faceF2F class. The activity portion is in green. The processing period is after the green. The red bars total 30minutes in the turn-taking, face-tofaceF2F interaction. The scale is expanded in this region so the red bars are proportional to time. Each row represents a participant in the discussion.

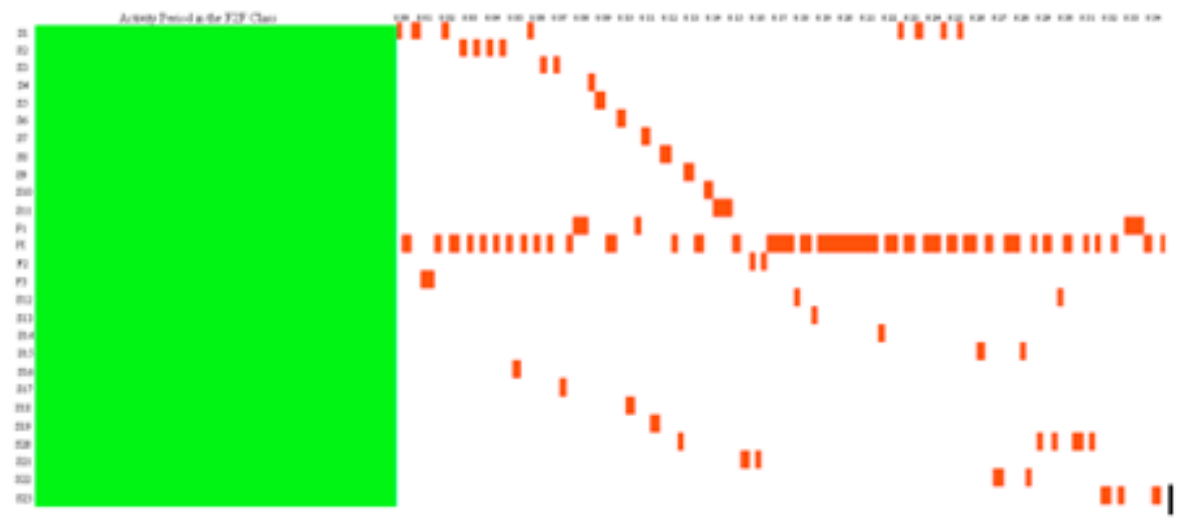

For the online class, the green bar on the upper left edge of Figure 4 identifies the 30 minutes of interaction during the activity portion of the class. It was observed that the online interaction was as vigorous and as distributed as F2F, the only difference being that the online statements were transparent and available to all participants as they unfolded. Each column in Figure 4 represents one minute of elapsed time during the online discussion. The red bars represent statements totaling 150 words. The blue bars in the same column represent the statements that would not be possible to make in any turn-taking environment due to the 150 word per minute limitation.

Figure 4. Time-use in the online class. The green bar represents the activity period. After the activity period, there are 30 columns, one per minute. The red bars total 30 minutes of statements, while the blue bars total 46 minutes - for a total effective time of 76 minutes worth of statements in the non turn-taking environment. Each row represents a participant in the discussion.

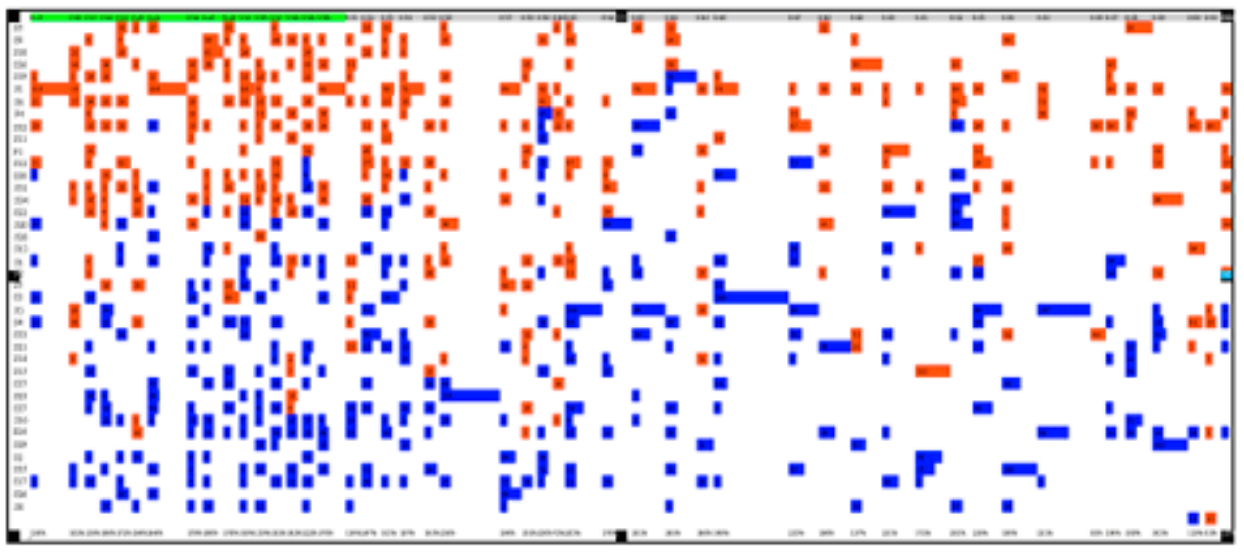




\section{Discussion}

The rows with blue bars in Figure 4 represent online students who would not have been able to speak F2F - even if they so desired - because there simply was not enough time.

This study shows that there is significantly more data flow in terms of words and statements generated in the LBD eClassroom $(\mathrm{C}$ than in the traditional F2F turn-taking settings. Evidence from this study also shows that online class students send and receive more statements among themselves compared to F2F students engaged in traditional classroom settings. It is postulated here, therefore, that this increase flow of statements between and among online participants facilitates the construction of 'collaborative knowledge.' Because data flow is also linked to 'trust formation' which is found by Gibb and other process theorists (see Lobel, Neubauer, and Swedburg, 2004) to be essential to learning, also suggests that trust levels (permission to share thoughts and ideas) is higher among online students than F2F students.

These findings point to significant differences between turn-taking and non-turn-taking interactions. This finding also raises several important questions: Do participants engaged in synchronous non-turn-taking interactions create more time for themselves? What are the implications/ applications of the extra 46 minutes it takes to read out the statements generated in a 30-minute real-time discussion with 35 other students versus F2F turn-taking instructor centered discussion? If time is money, do online participants benefit more than their F2F counterparts? And if so, how? If information is power (i.e., data flow generated in online classrooms is greater, more varied, visible, and lasting) are online students more productive and do they have a better sense of themselves and others?

\section{Conclusion}

This paper examines two findings of a matched-study designed to investigate similarities and differences between two teaching environments: traditional face-to-face (F2F) turn-taking environment; and an online non-turn-taking environment using the LBD eClassroom $\subset$. Two sections of the same course were taught online and F2F. The course objectives, content, and pedagogy (experiential learning) were the same for both the F2F and online sections, as were the teaching team, the time frames and class duration, course assignments and grading criteria.

One session described in this paper was randomly selected from the larger data pool. Perhaps because the most glaring differences between learning F2F and learning online relate to interactivity, the tone of this report may infer a preference for online education. This is not the case. Each environment has its distinct advantages. The issue here, therefore, is not which venue is better or worse. The intent of this inquiry was simply to understand - in terms of similarities and differences - online and F2F learning settings, findings upon which we hope can lead to more relevant online learning theories that result in improved teaching effectiveness across the board.

Interactivity is at the core of the course material used in the matched study. It is assumed that in an emotional climate of 'trust and acceptance,' and the data flow generated by participants in a group will lead to more effective goal formation, which in turn imparts a sense of control to those involved, which in turn further increase trust, data flow . . . and so on. Of course if this process reversed, it will produce the equivalent downward spiral: fear will lead to silence, which will reduce known options or choices and lead to low productivity and a sense of dissatisfaction with 
oneself and the group (Gibb, 1964). The course content and process is built on the rationale that visibility yields awareness, accountability, connection, which in turn enhances productivity and feelings of well being. Feedback and self disclosure are seen as effective tools for reducing the blind area in an individual's or a group's self awareness, thereby improving the entity's ability to do its work (Luft, 1969).

When comparing F2F to online interaction in the Main Group, the Participation Pattern Diagrams (Figure 2) point to distinctly different patterns of interaction in the two environments. F2F, the majority of verbal interactions were between the instructors and the students. Online, the instructor (as the hub of most statements) was replaced by a group-entity, akin to a polis; students interacted not only with their instructor, but also with each other to form a polis. Important differences in the sheer number of statements exchanged online compared to the number of statements exchanged F2F speaks to the higher level of data flow available to the online group and to the ability of the LBD eClassroom ${ }^{\complement}$ to facilitate such flow.

It was also postulated that the group entity (polis) is the repository of information that in F2F settings constitutes the constant hum-buzz of a classroom - information that would typically be buried and not available (e.g., not be published due to lack of time, participants' reticence to speak, and so on). This comparison validates our idea that F2F interactions in this study are basically expert-centered.

Perhaps the most surprising finding to emerge from this matched study - one that we feel may have the greatest implications and application - is the issue of hyper-time, or the extra time that is created online - time that allows for additional data flow and increased productivity. Foulger (2002) in: Building Time Machines: thinking about the future of interpersonal communication, discussed ways of "bending time" online. He defines "supersynchrony" as "receiver control of level of synchrony with parallel interactions" (http://foulger.info/davis/research/timeInMedia2/) wherein users have the ability to break and restore communication linearity. This means that the environment is collecting and making available all the statements exchanged thus far, so that all participants can scroll back from the moment the statements was posted, while interacting presently in the here-and-now, resulting in several conversations happening all at the same time (which are archived for later use). Such hyper synchronous, multi-layered online interaction not only connects each participant in a web of discussion, it affords each participant time to respond during the online synchronous discussion and time to reflect and digest what was said in the archives. The LBD eClassroom $(\subset)$ unfolds on a different timeline, one which produces and energizing learning experience while in progress, and an arena for reflective thought after it has finished. Simply put, it appears that the specific type of online communication observed creates more time!

\section{References}

Batagelj, V., and Mrvar, A. (1996). Pajek, a freeware software program for large network analysis. University of Ljubljana, Slovenia. Retrieved February 25, 2002, from: http://vlado.fmf.uni-lj.si/pub/networks/pajek/

Borgatti, S. P., Everett, M. G., and Freeman, L. C. (1999). UCINET 5.0 Version 1.00. Natick: Analytic Technologies.

Dewey, J. (1938; 1997). Experience and Education. New York: Simon and Schuster. 
Selected Topics from a Matched Study between a Face-to-face Section and a Real-Time Online Section of a University Course Lobel, Neubauer, \& Swedburg

Dimock, H. (1985). How to observe your group. Center for Human Resource Development Monograph Series for People working with People, $1-46$.

Foulger, D. (2002). Building Time Machines: Thinking about the future of interpersonal communication. Oswego State University Cognitive Science Lecture Series, 2002. Retrieved August 16, 2003 from: http://www.oswego.edu/ dfoulger/research/timeInMedia2/

Gibb, J. R. (1964). Climate for Trust Formation. In L. P. Bradford, J. R. Gibb, and K. Benne (Eds.) T-group Theory and Laboratory Method (279-309). New York: Wiley.

Kellogg, W., and Erickson, T. (2002). Social Translucence, Collective Awareness, and the Emergence of Place. Retrieved September 6, 2003 from: http://modiin.njit.edu/workshops/cscw2002/Kellogg.pdf

Kolb, D. A. (1984). Experiential Learning. Englewood Cliffs, NJ.: Prentice-Hall.

Lazarus, A. (1975). Learning to Relax (Tape). Institute for Rational Living, Inc.

Light, A. (2003). CHI 2003: How to Make Group Environments Social. Retrieved September 13, 2003 from: http://www.usabilitynews.com/news/article1237.asp

Lobel, M., Neubauer, M., and Swedburg, R. (2002a). Elements of group interaction in a real-time synchronous online learning-by-doing classroom without f2f participation. USDLA Journal. Retrieved May 5, 2002 from: http://www.usdla.org/html/journal/APR02 Issue/article01.html

Lobel, M., Neubauer, M., and Swedburg, R. (2002b). The eClassroom used as a Teacher's Training Laboratory to Measure the Impact of Group Facilitation on Attending, Participation, Interaction, and Involvement. International Review of Research in Open and Distance Learning, 3(2). Retrieved August 13, 2003 from: http://www.irrodl.org/content/v3.2/lns.html

Lobel, M., Neubauer, M., and Swedburg, R. (2004). Con-text? (An Inquiry) DEOSNEWS, 13(3). Retrieved December 20, 2005 from: http://www.ed.psu.edu/acsde/DEOSNEWS_13-3.pdf

Luft, J. (1969). Of Human Interaction. Palo Alto, CA.: National Press.

Moreno, J. L. (1934). Who shall survive? Washington, DC.: Nervous and Mental Disorders Publishing Co. (Reprinted 1953). New York: Beacon House.

Neubauer, M., and Lobel, M. (2003). The Learningbydoing eClassroom@: Learning Technology Task Force (LTTF). Journal of Learning Technology, 5(3), IEEE Computer Society. Retrieved August 12, 2003 from: http://lttf.ieee.org/learn_tech/issues/july2003/

Sanderson, G., Siple, L., and Lyons, B. (1999). Interpreting for Postsecondary Deaf. Report of the National Task Force on Quality of Services in the Postsecondary Education of Deaf and Hard of Hearing Students. Rochester, N.Y.: Northeast Technical Assistance Center, Rochester Institute of Technology. Retrieved August 16, 2003 from: http://www.rit.edu/ netac/publication/taskforce/interp/ 
Schultz, W. (1988). Profound Simplicity, 3rd Ed. Muir Beach, California: WSA.

\section{Appendix}

\section{Course Objectives}

\section{Session 1: Introduction}

Dates: Monday, September 16, 2002, and Thursday, September 19, 2002

- To unravel the logistics of the eClassroom and create technical protocols for eClass interaction

- To orient students in online interaction netiquette and culture

- To institute ground rules and appropriate behavioral norms

- To explore how to create a social presence online

- To introduce the process of writing your learning journal

\section{Session 2: Inclusion}

Dates: Monday, September 23, 2002, and Thursday, September 26, 2002

- To experience and observe how you negotiate membership in a group.

- To identify and articulate norms of human conduct.

- To demonstrate how self-disclosure is "icebreaking".

- To link your inclusion style to theory.

- To identify interpersonal strengths and limitation connecting with others.

\section{Session 3: Self Awareness}

Dates: Monday, September 30, 2002, and Thursday, October 3, 2002

- To illustrate the role self-awareness plays in effective interpersonal communications.

- To practice appropriate self-disclosure and appropriate feedback.

- To demonstrate how fear limits students' a ability and willingness to communicate effectively.

- To understand the role fear may play in achieving interpersonal needs or desires.

- To explore the skills needed to enlarge each student's, and the whole class's open area.

- To articulate observable, concrete, measurable steps to achieve a desired interpersonal goal.

\section{Session 4: Self-Disclosure/ Feedback/ Trust}

Dates: Monday, October 7, 2002 and Thursday October 10, 2002

- To experience the role of Self-Disclosure in interpersonal trust formation.

- To experience how we are more similar than different from each other.

- To experience how the awareness of 'being in the same boat' increases the willingness to communicate authentically

- To illustrate the roles and rules of Feedback in the communication process. 
- To commit to the process of increasing the Open Area of the community's Johari Window.

\section{Session 5: Values Clarification}

Date: Monday, October 21, 2002 and Thursday, October 24, 2002

- To experience the process of values clarification.

- To demonstrate the 'power' of diverse worldviews and to encourage acceptance of others.

- To increase awareness of interpersonal choice and response ability.

- To explore behavioral communication skills, like Active Listening, as useful tools for enhancing interpersonal connections.

- To introduce students to the concepts of problem solving and conflict management.

- To illustrate how people 'buy and sell' values.

- To practice collaborative behaviors based on accepting and valuing of diversity.

\section{Session 6: Perception}

Dates: Monday, October 28, 2002, and Thursday, October 31, 2002

- To explore issues in 'Perception' and to demonstrate the impact diverse phenomenological realities may have on interpersonal communications.

- To increase awareness of a natural tendency to make interpretations and react 'as if' these assumptions were absolute facts.

- To practice 'checking out' assumptions, before reacting to another.

- To demonstrate and encourage the acceptance of diversity.

\section{Session 7: Assertiveness}

Dates: Monday, November 4, 2002 and Thursday, November, 7, 2002

- To understand that 'assertiveness' 'aggressiveness' and 'passivity' are a set of beliefs, acquired skills and behaviors based on experience, which can be learned and can be unlearned.

- To define 'assertiveness' as:

o The ability to communicate clearly and honestly

o The courage to stand up for oneself without violating one's rights or another person's rights

o The willingness to express one's needs and feelings in ways, which reduce anxiety both for the sender and for the receiver.

o To familiarize students with the guide lines for appropriate assertive behaviors

o To explore available assertiveness training techniques and behavioral tools.

o To practice assertiveness by role-playing real life situations.

\section{Session 8: Assertiveness/ Conflict}

Dates: Monday, November 11, 2002, and Thursday, November 14, 2002 
- To facilitate students in identifying and understanding their own Conflict Management Styles.

- To increase awareness of the role emotion and values play in the conflict resolution process.

- To provide opportunities which facilitate the practice of collaborative skills building.

- To explore the advantages and disadvantages of the varied conflict resolution approaches, with a focus on collaboration and 'win/ win' outcomes.

- To increase awareness of negotiation skills.

- To provide a safe experiential opportunity for practicing Active Listening during a conflict situation.

\section{Session 9: Review/ Synthesis}

Dates: Monday, November 18, 2002, and Thursday, November 21, 2002

- To link the concepts covered in the course to practical experience.

- To provide an opportunity to review and practice the skills covered in the course.

- To reflect on the communication skills learned and identify the skills still in need improvement.

- To illustrate the roles our emotions and values play in maintaining interpersonal relationship and accomplishing the individuals' goals.

- To provide an opportunity, which facilitates the practice of collaborative skills building.

- To explore the advantages and disadvantages of the varied conflict resolution approaches, with a focus on collaboration and 'win/win' outcomes.

\section{Session 10: Gives and Gets}

Dates: Monday, November 25, 2002, and Thursday, November 28, 2002

- To review the topics covered

- To wrap up unfinished business

- To provide closure

- To facilitate an action plan for the future

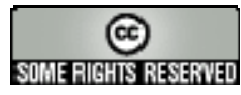

